\title{
THÀNH LẬP BẢN ĐỔ HIỆN TRẠNG CHẤT LƯợNG NƯỚC MẶT CUNG CẤP TRÊN MẠNG INTERNET
}

\author{
ThS. NGUYẼ̃N TH! CHI ${ }^{(1)}$ \\ ThS. BÙl TH! CÂMM NGỌC ${ }^{(2)}$ \\ (1) Viện Khoa học Đo đạc và Bản đồ \\ ${ }^{(2)}$ Trường Đại học Tài nguyên và Môi trường
}

\section{Tóm tắt:}

Bài báo đề xuất nội dung, phương pháp thể hiện, quy trình thành lập bản đồ hiện trạng chất lượng nước mặt trên mạng Internet bằng công nghệ mã nguồn mở Geoserver.

\section{Mở đầu}

Bản đồ hiện trạng chất lượng nước mặt trên mạng Internet là bản đồ môi trường thể hiện hiện trạng môi trường nước tại một thời điểm cụ thể và được xuất bản trên mạng Internet, có khả năng cập nhật tức thời dung lượng thông tin lớn và đáp ứng được đa dạng các đối tượng người sử dụng.

Việc xây dựng bản đồ hiện trạng chất lượng nước mặt trên mạng Internet không chỉ giúp ích cho công tác quản lý tài nguyên nước mà còn giúp cộng đồng có khả năng tiếp cận thông tin, nắm bắt tình hình ô nhiễm nước mặt một cách nhanh chóng, thuận tiện.

\section{Nội dung và phương pháp thể hiện}

Là một loại bản đồ môi trường, bản đồ hiện trạng chất lượng nước mặt trên mạng Internet cần thể hiện đầy đủ các yếu tố nội dung - cơ sở toán học, cơ sở địa lý và nội dung chuyên đề. Các yếu tố nội dung chuyên đề của bản đồ hiện trạng chất lượng nước mặt bao gồm mạng lưới các điểm quan trắc; ranh giới tự nhiên các lưu vực sông; các khu vực nhạy cảm môi trường, đất ngập nước; các đối tượng kinh tế - xã hội có liên quan đến chất lượng nước mặt.

Các phương pháp thể hiện được sử dụng cho nội dung chuyên đề của bản đồ hiện trạng chất lượng nước mặt trên mạng
Internet bao gồm phương pháp ký hiệu điểm, phương pháp khoanh vùng và phương pháp biểu đồ định vị. Các ký hiệu dạng điểm thể hiện vị trí các điểm quan trắc; phương pháp khoanh vùng để thể hiện các yếu tố nội dung chuyên đề khác như: nước mặt, các khu vực nhạy cảm môi trường, đất ngập nước, chỉ số chất lượng nước (WQI); phương pháp biểu đồ định vị để thể hiện giá trị WQI tại mỗi vị trí quan trắc dưới dạng biểu đồ hình cột. Phương pháp phân vùng giá trị WQI trên từng đoạn sông còn gặp nhiều khó khăn do sự hạn chế về số lượng điểm quan trắc. Ngược lại, phương pháp thể hiện giá trị WQI dưới dạng biểu đồ định vị có thể đánh giá được chất lượng nước tại thời điểm đo cho mỗi khu vực quan trắc.

\section{Chuẩn hóa dữ liệu sang dạng WEB} để phục vụ cho việc cập nhật thông tin về bản đồ hiện trạng chất lượng nước mặt.

WebGis là hệ thống thông tin địa lý phân tán trên một mạng máy tính để tích hợp, trao đổi các thông tin địa lý trên mạng diện rộng. Trong cách thực hiện nhiệm vụ phân tích, dịch vụ này gần giống như là kiến trúc khách - chủ (Client - Server). Xử lý thông tin địa lý được chia ra thành các nhiệm vụ ở phía máy chủ và phía máy khách. Điều này cho phép người dùng có thể truy xuất, thao tác và nhận kết quả từ việc khai thác dữ liệu GIS qua trình duyệt web mà không phải trả 
tiền cho phần mềm GIS.

WebGis làm cho các thông tin địa lý trở lên hữu dụng và sẵn sàng đến được với mọi người dùng trên toàn thế giới. Thách thức lớn của WEBGIS là việc tạo một hệ thống phần mềm không phụ thuộc vào nền tảng của thiết bị cuối và chạy trên chuẩn giao thức $T C P / I P$. Vấn đề này yêu cầu các phần mềm GIS phải được thiết kế lại để trở thành ứng dụng WebGis trong môi trường Internet đa người dùng.

GeoServer là một máy chủ mã nguồn mở với mục đích kết nối những thông tin địa lý có sẵn tới các Geoweb (trang Web địa lý) sử dụng chuẩn mở. GeoServer được viết bằng ngôn ngữ Java, cho phép người sử dụng chia sẻ và chỉnh sửa dữ liệu không gian địa lý (geospatial data), tạo bản đồ và xuất ra nhiều định dạng. Tương thích với chuẩn Web Feature Service (WFS), GeoServer cho phép chia sẻ và chỉnh sửa dữ liệu đang được dùng để hiển thị bản đồ. GeoServer sử dụng tập tin có đuôi mở rộng là SLD (Styled Layer Descriptor) để tạo kiểu thể hiện bản đồ (style) theo chuẩn WMS, tập tin SLD được cấu trúc theo định dạng XML (Extensible Markup Language). [3]

\section{Kết quả nghiên cứu}

Quy trình thành lập bản đồ chất lượng nước mặt trên mạng Internet được xây dựng phù hợp với Thông tư số 17/2011/TT - BTNMT ngày 08 tháng 6 năm 2011 về quy trình kỹ thuật thành lập bản đồ môi trường không khí, nước mặt lục địa, nước biển. (Xem hinh 1)

Biên tập khoa học là việc xác định vùng thành lập bản đồ; xác định chủ đề, mục đích của bản đồ và đặt tên bản đồ; xác định dạng bản đồ sản phẩm, tên trang WEB, định dạng bản đồ trên WEB.

Công tác chuẩn bị gồm có chuẩn bị bản đồ nền; thu thập, tập hợp số liệu quan trắc; thu thập dữ liệu chuyên đề về môi trường nước mặt , xác định điểm quan trắc trên bản đồ nền và thực hiện quan trắc, phân tích mẫu quan trắc.

Biên tập bản đồ dạng shapfile là thực hiện việc biên tập các yếu tố nền địa lý và biên tập các yếu tố nội dung theo chuyên đề về môi trường nước mặt. Trong quá trình biên tập phải chỉnh hợp các yếu tố chuyên đề trên bản đồ nền để đảm bảo tương quan địa lý giữa chúng.

Chuẩn hóa dữ liệu sang dạng web là quá trình thực hiện tạo kiểu file (chuẩn hóa) bằng cách đăng nhập vào Geoserver, tạo kiểu file, viết mã kiểu file (có thể viết tay các đoạn mã hoặc sử dụng công cụ mã nguồn mở). Sau khi tạo xong các file style cho từng lớp, tiến hành gán style tương ứng cho từng lớp. Các lớp dữ liệu sau khi chuẩn sang định dạng web, sẽ được đẩy lên Geoserver.

Trang web được xây dựng, ngoài việc hiển thị, cập nhật dữ liệu quan trắc đa thời gian còn phát triển thêm một số chức năng mới như: Cập nhập thêm điểm quan trắc mới, hiển thị số liệu quan trắc dưới dạng biểu đồ, thực hiện các báo cáo số liệu quan trắc và thể hiện bản đồ mạng lưới quan trắc môi trường nước mặt trực tuyến tích hợp với Google Map.

Website tích hợp GIS có bộ công cụ truy vấn đơn giản, dễ sử dụng. Trang web được xây dựng dựa trên công nghệ mã nguồn mở Geoserver kết nối thông tin từ Google map kết hợp với Openlayer còn giúp tăng khả năng chia sẻ dữ liệu trên Internet. (Xem hinh 2, 3, 4)

\section{Kết luận}

Quy trình thành lập bản đồ chất lượng nước mặt trên mạng Internet được xây dựng phù hợp với quy định hiện hành về thành lập bản đồ môi trường, đáp ứng các yêu câu kỹ thuật, có khả năng ứng dụng trong thực tiễn. Việc đưa bản đồ hiện trạng chất lượng nước mặt lên mạng Internet đáp 


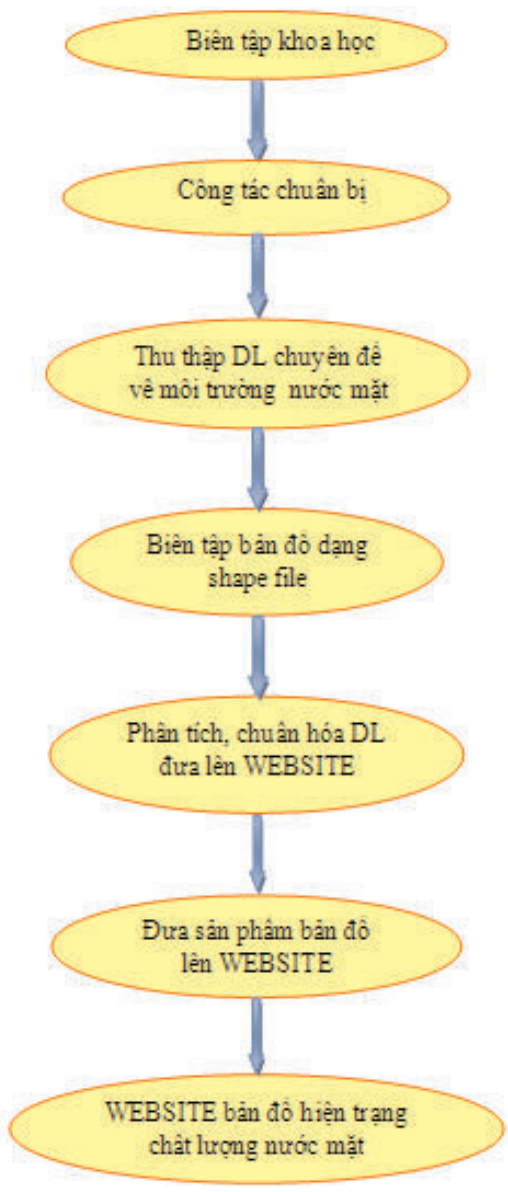

Hình 1: Quy trình thành lập $B \boxminus$ hiện trạng chất lượng nước mặt trên mạng Internet

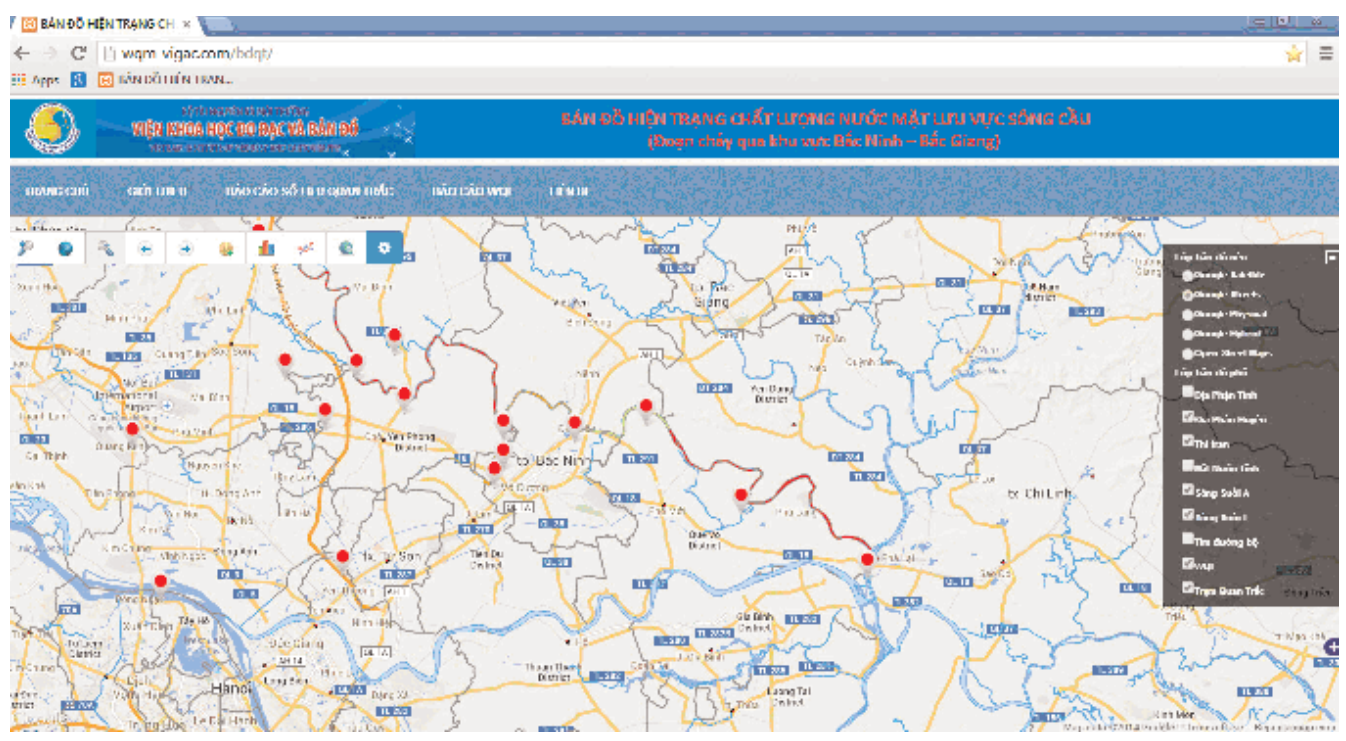

Hình 2: Trang WEB bản đồ hiện trạng chất lượng nước mặt tích hợp trên Google Map 


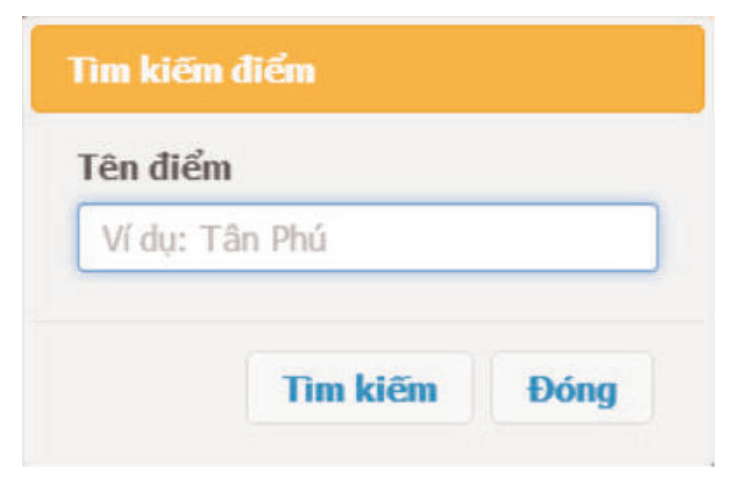

Tìm kiếm theo trạm

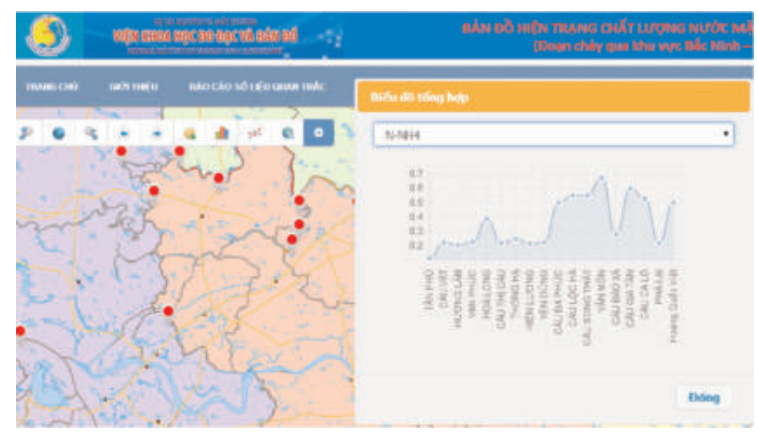

Hình 3: Hiển thị số liệu quan trắc dưới dạng biểu đồ hình tuyến

ứng nhu cầu sử dụng của cả ba nhóm đối tượng - cơ quan quản lý, các nhà nghiên cứu và cộng đồng.

Trang web được xây dựng ngoài việc cập nhật dữ liệu quan trắc đa thời gian còn cho phép cập nhật thêm các điểm quan trắc mới, hiển thị số liệu quan trắc dưới dạng biểu đồ. Lựa chọn công nghệ mã nguồn mở Geoserver kết nối thông tin với Google map tạo ra cơ hội để người sử dụng đều có thể tiếp cận dữ liệu và các chức năng của GIS một cách dễ dàng mà không cần cài đặt bất

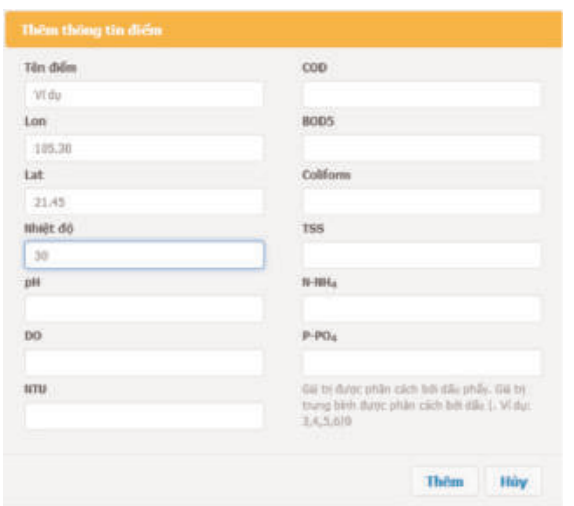

Thêm móri điểm quan trắc

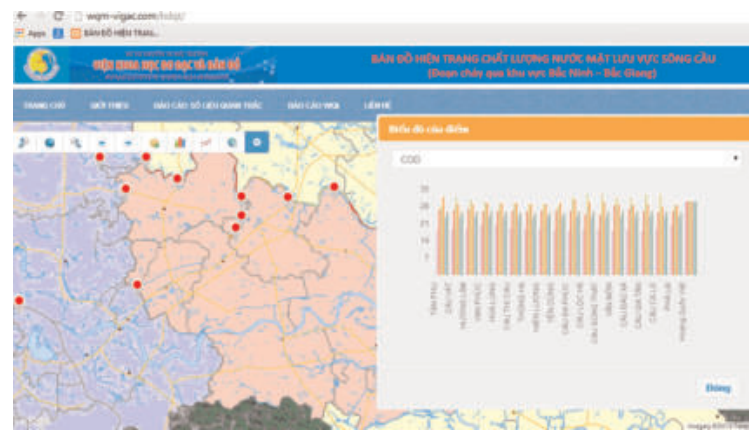

Hình 4: Hiển thị số liệu quan trắc dưới dạng biểu đồ hình cột

kỳ một phần mềm GIS chuyên dụng nào. $O$

\section{Tài liệu tham khảo}

[1]. Bộ Tài nguyên và Môi trường (2011), Thông tư Quy định về Quy trình kỹ thuật thành lập bản đồ môi trường (không khí, nước mặt lục địa, nước biển).

[2]. Bộ Tài nguyên và Môi trường (2008), Quy chuẩn kỹ thuật Quốc gia về chất lượng nước mặt, Hà Nội.

[3]. Website http://voer.edu.vn/m/geoserver/7b79cf59. 0

\section{Summary}

\section{Establishing the current surface water quality map on the internet by Geoserver}

MSc. Nguyen Thi Chi - Institute of Geodesy and Cartography

MSc. Bui Thi Cam Ngoc - Hanoi University of Natutal Resources and Environment.

This report will provide contents, methods and procedures for surface water quality map establishment on the Internet by Geoserver. $O$

Ngày nhận bài: 20/02/2015. 